\title{
Interactive comment on "Organic aerosol source apportionment in Zurich using an extractive electrospray ionization time-of-flight mass spectrometry (EESI-TOF): Part II, biomass burning influences in winter" by L. Qi et al.
}

L. Qi et al.

lu.qi@psi.ch

Received and published: 28 May 2019

The comment was uploaded in the form of a supplement:

https://www.atmos-chem-phys-discuss.net/acp-2019-64/acp-2019-64-AC3-

supplement.pdf 